DOI 10.37882/2223-2982.2021.01.36 \title{
ВИДЕОВЕРБАЛЬНЫЙ ЭЛЕКТРОННЫЙ НАУЧНО-ПОПУЛЯРНЫЙ ТЕКСТ КАК ЦЕЛОСТНОЕ ИНФОРМАЦИОННОЕ ПРОСТРАНСТВО
}

\section{VIDEO-VERBAL ELECTRONIC POPULAR SCIENCE TEXT AS AN INTEGRAL INFORMATION SPACE}

\section{N. Khristoforova}

Summary: The article deals with video-verbal popular science texts that are a part of the modern communication space. They are widely used in electronic versions of popular science publications, providing readers with the latest information from the field of science. The article considers the specifics of electronic popular science text, which is caused by the presence of semantically equivalent verbal and non-verbal elements. The article concludes that the use of video-verbal text has a positive effect on the process of obtaining complex scientific information by nonspecialist readers. The semantic deployment of the topic of an electronic popular science text becomes complete due to the combination of verbal and non-verbal components in the reader's mind during the reading of this text, while polycode elements significantly expand the semantic potential of an electronic popular science text.

The research material was popular science texts from electronic versions of the journals "Bild der Wissenschaft», "ScienceBlogs», «GEO».

Keywords: internet space, video-verbal text, electronic popular science text, verbal components, non-verbal components.
Христофорова Наталья Игоревна

к.фрилол.н., доцент, ФГБОУ ВО «Московский авиационный институт (национальный исследовательский университет)», г. Москва n_khristoforova@mail.ru

Аннотация: В статье рассматриваются видеовербальные научно-популярные тексты, являющиеся частью современного коммуникативного пространства. Они широко используются в электронных вариантах научно-популярных изданий, предоставляя читателям новейшую информацию из области науки. Рассматривается специфика электронного научно-популярного текста, которая обусловлена присутствием семантически равнозначных вербальных и невербальных элементов.

В статье сделан вывод о том, что использование видеовербального текста положительно влияет на процесс получения сложной научной информации читателями-неспециалистами. Семантическое развертывание темы электронного научно-популярного текста становится полным благодаря соединению вербальных и невербальных компонентов в сознании читателя в процессе чтения, при этом поликодовые элементы в значительной степени обеспечивают расширение семантического потенциала электронного научно-популярного текста.

Материалом исследования послужили научно-популярные тексты из электронных вариантов журналов «Bild der Wissenschaft», «ScienceBlogs», "GE0».

Ключевые слова: интернет-пространство, видеовербальный текст, электронный научно-популярный текст, вербальные компоненты, невербальные компоненты.

можность поместить в него разнородную информацию, необходимую для понимания его содержания.

Несмотря на большой интерес со стороны исследователей, единого терминологического обозначения семиотически неоднородных явлений нет. Применяются термины: креолизованный текст (Ю.А. Сорокин, Е.Ф. Тарасов, Е.Е. Анисимова); гетерогенный текст (А.Г. Сонин, М.А. Ищук); изовербальный текст (А.А. Бернацкая); лингвовизуальный текст (Л.М. Большиянова); видеовербальный текст (О.В. Пойманова); поликодовые тексты (Г.В. Ейгер, В.Л. Юхт, А.Г. Сонин, А.В. Алферов); коммуникат (В.Е. Чернявская); визуальные тексты (А.А. Корниенко). Мы используем термин «видеовербальный текст», поскольку, на наш взгляд, он наиболее полно отражает специфику данного явления.

Представляется важным рассматривать сочетание вербальной и невербальной коммуникации в процессе создания научно-популярного текста. При этом отметим, что в таком тексте плотность информации, переданной невербальными средствами, часто выше, чем в его вербальной составляющей. Следовательно, при интерпре- 
тации видеовербального текста происходит «двойное декодирование информации: извлечение концепта из невербальной части и последующее его совмещение с вербальной частью, что приводит к более глубокому и целостному пониманию смысла... текста... В полной мере реализуется принцип наглядности, причём на уровне анализа взаимосвязи зрительного и вербального рядов, который проявляется в неоднократном обращении... то к изображению, то к тексту...» [3].

Сочетание вербального и невербального компонентов научно-популярного текста позволяет сделать его интереснее и эффективнее для читателя-неспециалиста в рассматриваемой области, для которого и создаются такие тексты. Развитие семиотического направления в лингвистике стало началом научного рассмотрения текстов с невербальной составляющей, что было обусловлено изучением изображения как особой знаковой системы, а также возможностей ее использования. «Контакт с любым зрительным образом происходит быстрее, чем контакт с вербальной информацией, поскольку восприятие и её фиксация в памяти занимает меньше времени, чем восприятие буквенного изображения слова» [4]. Отметим, что видеовербальный текст явление сложное, так как он состоит из разнородных составляющих, связанных при этом функционально и семантически, и представляет собой структурное целое, восприятие и интерпретация которого зависят в равной степени от всех его составляющих. Такой текст состоит из сочетания вербальных и невербальных элементов, которые читатель может интерпретировать в процессе ознакомления с текстом. Намерение автора текста реализуется в полной мере и не вызывает затруднений «при правильной комбинации знаков вне зависимости от объема текста» [5]. В видеовербальных текстах основную роль играют невербальные элементы, которые интегрированы в текст по смыслу и композиционно. Вербальные и невербальные элементы текста функционируют в едином семантическом пространстве, благодаря чему формируется связность и целостность текста и достигается определенный эффект - пробуждение интереса у читателя, его информирование, формирование у него отношения к этой информации, побуждение к действию. В процессе изучения текста читатель декодирует заложенную в тексте информацию (в вербальной и невербальной составляющих), получая в итоге смысл видеовербального текста. Отметим, что научно-популярные видеовербальные тексты характеризуются взаимозависимостью вербального и невербального компонентов, что формирует новый способ передачи информации, а также создает ее новый смысл: невербальные элементы придают словам дополнительное значение. При этом для автора научнопопулярного текста важно исключить иное толкование информации, новой для читателя-неспециалиста, кроме заложенного, запланированного. Рассмотрим это на конкретном примере. В тексте о пятнах на Солнце [6] приведена цветная фотография (с возможностью увеличения) этого явления, снятая с максимальным разрешением. У фотографии есть подпись: Ein Sonnenfleck in höchster Auflösung, beobachtet mit dem Gregor-Teleskop (Пятно на Солнце, максимальное разрешение. Снимок сделан с помощью телескопа Грегори). При отсутствии подписи к фотографии, читатель сделал бы вывод о том, что изображено, на основании личного опыта и знаний, однако уверенности, что читатель узнал бы именно пятно на Солнце нет. Текст завершается следующим предложением: Die Bildausschnitte aus dem Juli 2020, die einem grobschuppigen Drachenauge ähneln, zeigen unter anderem die Entwicklung von Sonnenflecken und die komplexen Strukturen des Sonnenplasmas. - Кадры наблюдений, сделанных в июле 2020, которые показывают развитие пятен на Солнце и сложных структур солнечной плазмы. В этом же предложении приводится сравнение: einem grobschuppigen Drachenauge ähneln (похожи на чешуйчатый глаз дракона). Предположительно, такой образ, несмотря на свою сказочность, будет близок читателю, ведь в настоящее время образ дракона очень популярен и встречается в фильмах, мультфильмах, компьютерных играх. Кроме того, возможно формирование в сознании у читателя образной параллели, облегчающей понимание и запоминание информации, которую можно изобразить так: глаз дракона = пятно на Солнце = необычное, далекое, огромное, реальное и в тоже время нереальное, «исследователи смогли взглянуть на глаз дракона».

Особые возможности для создания и функционирования видеовербальных текстов предоставляет глобальная информационная сеть (Интернет) как форма информационно-коммуникативного пространства. Эта коммуникативная среда дала возможность расширения возможностей применения видеовербальных текстов, что привело к возникновению особого вида текстов электронных научно-популярных текстов. В связи с этим формируется особая дисциплинарная парадигма - лингвистика Интернета. В настоящее время электронный текст вошёл во многие области человеческого общения, а изучение природы такого текста, его семантики и функциональности в современном языкознании выходит далеко за рамки замкнутой текстовой структуры. «Вербальный код является основным, но далеко не доминирующим элементом в поликодовом пространстве современной коммуникации» [7], таким образом, электронный текст можно рассматривать как текст, существующий только в глобальной информационной сети Интернет или на автономном носителе электронных данных, причем его вербальная и невербальная составляющие образуют единое визуальное, структурное, смысловое и функциональное целое. Связность элементов электронного научно-популярного текста на семантическом уровне проявляется в структурном, идентифицирующем и дейктическом аспектах, причем каждый из которых ак- 
туализируется с помощью вербальных и невербальных единиц электронного текста. Семантическое развертывание темы электронного научно-популярного текста становится полным только тогда, когда вербальные компоненты соединяются в сознании читателя с визуальной составляющей. Можно говорить о том, что связность элементов электронного научно-популярного текста не зависит исключительно от вербальной составляющей, которая в некоторых моментах (с учетом возрастающей доли визуальных материалов в электронных текстах) является избыточным элементом.

К преимуществам электронных ресурсов по сравнению с иными формами распространения информации относятся их интерактивность, мультимедийность, глобальность, оперативность и гипертекстуальность. Отметим, что в настоящее время для достижения поставленных целей построение научно-популярного текста происходит по аналогии с построением сайтов: такой текст не просто предоставляет читателю-неспециалисту информацию (новость) из мира науки, старается вызвать интерес к этой информации, побудить читателя согласиться с оценкой описываемых фактов, но и старается сделать это аналогично представлению информации на интернет-страницах. В первую очередь это достигается с помощью невербальных компонентов текста: для электронного научно-популярного текста характерно широкое применение невербального материала: фотографий, рисунков, видеоматериалов, цвета, шрифта, фона и т.д.

Сочетание в тексте вербальных и невербальных средств коррелирует с вербальной стороной интернеткоммуникации, проявляя слово и образ как единое целое. А поскольку «в информационных системах парадигматические отношения следуют по вектору упрощения восприятия контента» [4], то применение зрительных образов становится основным средством достижения этого упрощения. Видеовербальный электронный текст позволяет «функционировать большому объему информации в более сжатом пространстве» $[8,65]$. Используя невербальную составляющую можно снизить объем текста при максимальном увеличении смысловой нагрузки. Особую роль в электронных научно-популярных текстах играют видеофайлы: часто они содержат три важных элемента, привлекающих внимание, информирующих, помогающих лучше понять и усвоить информацию. Это видеоизображение, подписи к нему, а также звуковой ряд. Так, например, текст [9], рассказывающий об озере Лох-Несс, всемирно известном Лох-Несском чудовище, и содержащий фотографии и гиперссылки на другие материалы той же тематики, завершается приглашением поучаствовать в дискуссии, существует ли это чудовище, поскольку до сих пор определенного ответа на вопрос нет, и приглашением посмотреть видеоматериал: Diese TerraX-Folge dürfte interessant sein: "Geheimnisse von Loch Ness" - «Тайны озера Лох-Несс» это интересно». В видео- материале рассказывается (диктором и исследователем) о природе вокруг озера, его древних и современных обитателях, о геологических процессах, происходивших в древности и сформировавших современный облик озера. В видеофайле используются кадры, снятые современной техникой, а также фотографии и реконструкции с помощью компьютерной графики в сопровождении кратких подписей, указывающих на наиболее значимые моменты.

В видеовербальных научно-популярных текстах невербальная составляющая оказывает решающее значение на восприятие текста, контролируя способ его построения. Эта составляющая делает текст более наглядным и эмоционально окрашенным, привлекая внимание читателя. В процессе чтения видеовербального текста постоянно происходит распределение внимания между его вербальными и невербальными компонентами, причём эти компоненты связаны на уровне содержания, композиции и языка. Исходя из этого, можно предположить, что электронный научно-популярный текст представляет собой видеовербальный текст с явно выраженными вербальной и невербальной составляющей, взаимодействующими между собой.

Например, текст [10] начинается с цветного рисунка-реконструкции: два ископаемых птеродактиля (птерозавра), один с оперением, другой - без него. Рисунок можно увеличить и рассмотреть подробнее. На синем фоне размещена подпись - пояснение содержания текста, а также указывается автор рисунка (сотрудница Портсмутского университета):

Wie weit reicht die Evolutionsgeschichte der Feder zurück? Ob auch die Pterosaurier Urformen dieser Struktur besaßen, spielt bei dieser Frage eine wichtige Rolle. (Bild: Megan Jacobs, University of Portsmouth) - Сколько существуют перья? Чтобы ответить на этот вопрос, необходимо выяснить, были ли их ранние формы у птерозавров.

Второй элемент, привлекающий внимание - заголовок текста. Его шрифт больше размером, а цвет - синий, в отличие от цвета шрифта текста.

Streit um Flugsaurier-„„Federn“ - Спор о «перьях» птеродактилей.

Возможно ли в данном тексте существование вербальной составляющей без невербальной? Будет ли понятен смысл текста читателю-неспециалисту, для которого написан текст, если исключить рисунок-реконструкцию? Ответ однозначный: нет. Читатель либо не заинтересуется текстом, либо, начав читать, будет вынужден искать изображение птерозавров (неспециалист вряд ли сразу вспомнит, как они выглядели, согласно имеющимся данным). Возможно, изображения легко 
найти в Интернете по запросу, но захочет ли читатель заниматься поиском - неизвестно. Кроме того, рисунокреконструкция является и приглашением читателя к размышлению, кто же именно прав в споре исследователей, были ли у птеродактилей перья или нет. Если исключить и этот момент, значительно понижается интерес читателя и к тексту, и к рассматриваемому вопросу.

Таким образом, можно говорить о видеовербальном электронном тексте как о тексте, который может привлекать внимание к главному, «концентрировать» информацию и упрощать её восприятие. В данном типе текста невербальные компоненты выполняют следующие информативные функции: они дополняют сокращенную информацию, заменяют вербальный компонент (например, подробное описание объекта, рассматриваемого в тексте), а также, в сочетании с вербальным компонентом, акцентируют внимание читателя на наиболее значимой информации.

Научно-популярный текст адаптируется к электронному пространству, при этом объединяя в себе компоненты, которые, на первый взгляд, невозмож- но объединить. Видеовербальный электронный текст расширяет рамки двухмерного линейного текста, при чтении которого информация воспринимается последовательно, а его пространство ограничено. Видеовербальный электронный текст «нелинейный многомерный текст с поперечным измерением... это целостный текст... бесконечный, это готовое единое смысловое целое, подверженное совершенствованию, посредством изображений» $[8,68]$. Очевидно, что благодаря сочетанию вербального и невербального компонентов текста полученная информация воспринимается и перерабатывается максимально полно, а два способа представления информации облегчают ее получение, что особенно важно для читателя-неспециалиста. Следовательно, можно говорить о восприятии достаточно сложной информации с помощью визуального анализа и о том, что именно сочетание вербальных и невербальных элементов видеовербального электронного научно-популярного текста обеспечивает эффективность его функционирования в современных условиях использования Интернета. «Гибридный» формат такого текста определяет новый формат научно-популярных публикаций.

\section{ЛИТЕРАТУРА}

1. Качмазова А.У. Креолизованный текст как жанр интернет-дискурса//Актуальные проблемы филологии и педагогической лингвистики, Владикавказ, 2016. № 3, с. 108-110. Стр. 108

2. Вольская Н.Н. Оценка и её функции в креолизованном тексте карикатуры//Научный журнал «Дискурс-Пи», Екатеринбург, 2016. № 3-4 (24-26), с. 120-126. Стр. 124

3. Чернышенко 0.В. Лингводидактический потенциал креолизованного текста в рамках компетентностного подхода//Казанский педагогически журнал, Казань, 2016, №5 (118), с. 155-159. Стр. 156

4. Бочарова А.В. Особенности симбиотических отношений вербальной и невербальной знаковых систем в контексте интернет-коммуникации//Филологические науки. Вопросы теории и практики, Тамбов: Грамота, 2016. № 7(61): в 3-х ч., ч. 2, с. 56-60. Стр. 59

5. Громова Н.С. Специфика интерпретации многокомпонентного креолизованного текста//Вестник КГУ им. Н.А. Некрасова, Языкознание, Кострома, 2016, №2, c. 156-160. Стр. 157

6. Thome, Matthias. Gregor-Teleskop Forschern gelingt messerscharfe Nahaufnahme der Sonne// GE0. 2020. [электронный ресурс] - Режим доступа. - URL: https://www.geo.de/wissen/weltall/23272-rtkl-gregor-teleskop-forschern-gelingt-messerscharfe-nahaufnahme-der-sonne (дата 0бращения: 09.10.2020 г.)

7. учина С.А. Особенности реализации категории связности в электронных художественных текстах: семантический и визуально-графический аспекты// Вестник КГУ, Кемерово, 2018, №2 (74), с. 190-198. Стр. 190

8. Чижикова С.Н. Вербальные и невербальные компоненты в креолизованных текстах (на примере мультимедийных презентаций)//Научно-методический электронный журнал «Концепт», 2016, Выпуск № 07 (кафедра иностранных языков КВВАУЛ, г. Краснодар). - С. 64-69. Стр. 65, 68

9. Wurche Bettina. Monster-Suche im Loch Ness - ist es Nessie?//ScienceBlogs. 2020. [электронный ресурс] - Режим доступа. - URL: https://scienceblogs.de/ meertext/2020/06/25/monster-suche-im-loch-ness-ist-es-nessie/(дата обращения: 25.06.2020 г.)

10. Vieweg Martin. Streit um Flugsaurier-„,Federn“ Bild der Wissenschaft. 2020. [Электронный ресурс] — Режим доступа. — URL: https://www.wissenschaft.de/ erde-klima/streit-um-flugsaurier-federn/(дата обращения: 29.09 .2020 г.)

(c) Христофорова Наталья Игоревна (n_khristoforova@mail.ru).

Журнал «Современная наука: актуальные проблемы теории и практики» 